J-ABDIPAMAS (Jurnal Pengabdian Kepada Masyarakat)

Vol. $4 \bullet$ No. $2 \bullet 2020$

ISSN : 2581-1320 (Print) ISSN : 2581-2572 (Online)

Homepage: http://ejurnal.ikippgribojonegoro.ac.id/index.php/J-ABDIPAMAS

\title{
PELATIHAN PEMBUATAN MADING DUA DIMENSI DI SMPN 30 SURABAYA
}

\author{
Windi Setiawan ${ }^{1}$, Imayah $^{2}$, Edy Widayat ${ }^{3}$ \\ ${ }^{1}$ Universitas Dr. Soetomo. Email: windi.s@unitomo.ac.id \\ 2Universitas Dr. Soetomo. Email: imayah@unitomo.ac.id \\ 3Universitas Dr. Soetomo. Email: edy.widayat@unitomo.ac.id
}

\begin{abstract}
The wall magazine is one of the means to gather students' creativity at school. Its existence indirectly is able to make students to dare to express their creative ideas in the form of poetry, short stories, or other works that can be visualized. SMPN 30 Surabaya is a school that has complete facilities. It's just that bulletin boards at the school don't attract students to work. So, there is a need for training in making two-dimensional wall magazine to make it more interesting. The Unitomo Community Service Team is conducting training in this regard. The assistance was carried out in three stages namely. The planning phase, the implementation phase, and the reflection phase. At the planning stage, the service team and partners coordinate about the time of service delivery. At the implementation stage, the service team provides assistance to students in making twodimensional wall stickers. Then, at the reflection stage, the service team and partners discussed the sustainability of bulletin boards so that they could run in a sustainable manner.
\end{abstract}

Keywords: magazine, wall magazine, two dimensions

\begin{abstract}
ABSTRAK
Majalah dinding adalah salah satu sarana untuk menghimpun kreatifitas siswa-siswi di sekolah. Keberadaanya secara tidak langsung mampu membuat siswa untuk berani mengeluarkan ide kreatifnya baik dalam bentuk puisi, cerita pendek, atau karya lain yang dapat divisualisasikan. SMPN 30 Surabaya adalah satu sekolah yang memiliki fasilitas lengkap. Hanya saja papan buleting di seolah tidak menarik siswa untuk berkarya. Sehingga mereka membutuhkan pelatihan pembuatan mading dua dimensi agar tampak lebih menarik. Tim pengabdian masyarakat Unitomo kali ini melakukan pelatihan berkaitan dengan hal tersebut. Pendampigan dilaksanakan dalam tiga tahap yaitu tahap perencanaan, pelaksanaan, dan refleksi. Pada tahap perencanaan, tim pengabdi bersama mitra berkoordinasi mengenai waktu pelaksanaan pemgabdian. Pada tahap pelaksanaan, tim pengabdi melakukan pendampingan kepada siswa dalam membuat mading dua dimensi. Selanjutnya, pada tahap refleksi, tim pengabdian dan mitra mendiskusikan mengenai keberlanjutan mading agar bisa berjalan secara berkesinambungan.
\end{abstract}

Kata Kunci: majalah, majalah dinding, dua dimensi

\section{PENDAHULUAN}

Mitra pada program pengabdian masyarakat ini adalah SMPN 30 Surabaya yang berlokasi di Jl. Medokan Semampir Indah 119, Surabaya, Jawa Timur. SMP Negeri 30 Surabaya merupakan salah satu Sekolah Menengah Pertama Negeri yang ada di Provinsi Jawa Timur, Indonesia. Fasilitas yang dimiliki oleh SMPN 30 Surabaya termasuk kategori baik. Jumlah ruang kelas yang ada yaitu 35 ruangan dengan perincian 10 ruangan kelas VII, 11 ruangan kelas VIII, 10 ruangan kelas IX, 1 ruang pintar, 1 ruang tata boga dan 2 ruang teori. Setiap ruangan dilengkapi dengan LCD prokyektor. 
Fasilitas pembelajaran di SMPN 30 Surabaya sudah memadai hanya saja kemampuan menulis siswa kurang memuaskan dan minat membaca siswa masih sangat rendah. Hal ini dibuktikan dengan adanya majalan dinding yang tidak terisi dengan topic yang menarik. Disisi yang lain ketika ada siswa yang mempunyai minat untuk menulis sering kali terkendala atas ketiadaan fasilitas yang mampu menampung dan mengakomodasi ide-ide mereka. Berdasarkan permasalahan yang diuraikan ini maka perlu dibuat media pembelajaran berupa majalah dinding yang tujuannya untuk menampung kreativitas karya tulis siswa, untuk meningkatkan minat membaca siswa, meningkatkan keterampilan siswa dalam menulis karya tulis. Majalah dinding merupakan salah satu wujud keterampilan menulis dan merupakan media komunikasi yang paling sederhana. Menurut Supriyanto majalah dinding sangat mungkin diselenggarakan karena merupakan salah satu bentuk majalah sekolah yang sederhana dengan biaya yang murah sehingga lebih mungkin dilaksanakan dimana saja. Majalah dinding bukanlah hal baru dan asing dalam dunia persekolahan. Dalam praktiknya terdapat banyak bukti bahwa majalah dinding dapat menjadi sarana berlatih untuk membina kreativitas menulis dan modal penanaman gemar membaca pada siswa. Adapun beberapa manfaat manjalah dinding yaitu sebagai media komunikasi, wadah kreatifitas, menanamkan kebiasaan membaca, pengisi waktu, melatih kecerdasan berpikir, melatih berorganisasi, mendorong latihan menulis.

Dengan mengetahui bahwa majalah dinding sangat bermanfaat, maka perlu di kenalkan kepada siswa sejak dini. Sehingga tim pelaksana program pengabdian merencanakan suatu pembuatan majalah dinding kepada siswa/siswi SMPN 30 Surabaya. Langkah awal sebelum pelaksanaan program ini, team pelaksana melakukan observasi keadaan majalah dinding di SMPN 30 Surabaya. Tujuan dari melakukan observasi ini adalah untuk mendapat informasi yang berkaitan dengan majalah dinding yang ada SMPN 30 Surabaya. Dari informasi yang telah terkumpul maka tim pelaksana akan merencanakan langkah selanjutnya yang harus dilakukan, dilihat dari kondisi majalah dinding yang ada di SMPN 30 Surabaya. Berikut akan di tunjukan beberapa foto majalah dinding hasil observasi.

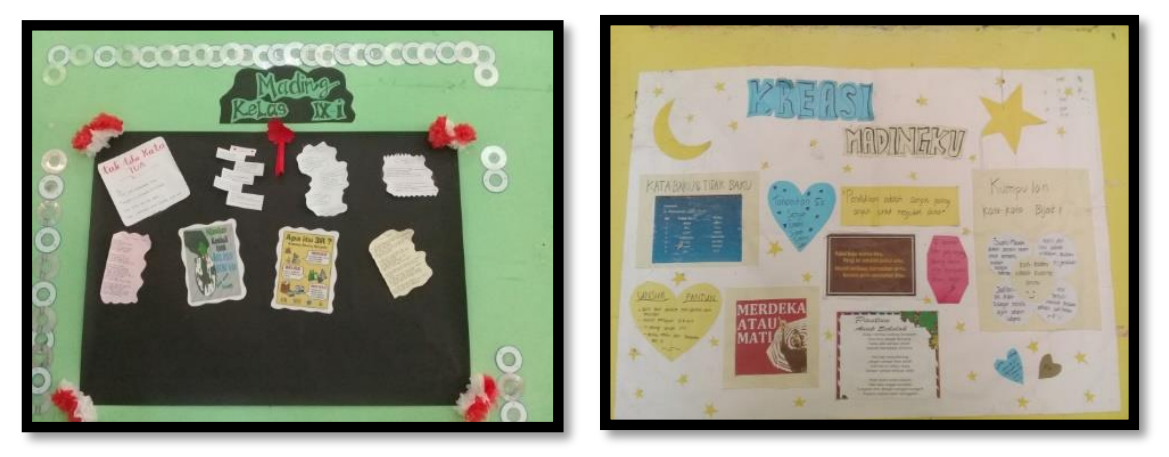

Gambar 1. Mading dua dimensi hasil observasi

Dari hasil observasi yang dilakukan ditemukan beberapa kelas sudah mempunyai inisiatif untuk membuat majalah dinding namun banyak dari majalah dinding ini isinya diambil dari internet sehingga manfaat dari majalah dinding yaitu melatih kecerdasan 
berpikir dan mendorong latihan menulis siswa tidak terrealisasi dengan baik. Adapun beberapa majalah dinding ini dibuat dengan isi yang sama misalkan dalam satu majalah dinding hanya di isi dengan kumpulan puisi atau kumpulan biografi. Dengan melihat masalah seperti ini tim pelaksana program pengabdian bekerja sama dengan guru-guru yang terlibat dalam team program kerja (POKJA) sekolah SMPN 30 Surabaya mengadakan kelas pokja mading untuk kelas VII yang terdiri dari 20 siswa dan kelas VIII yang terdiri dari 24 siswa. Mengacu pada analisis situasi, permasalahan yang dihadapi mitra adalah:

1. Siswa SMPN 30 Surabaya kurang memahami konsep dasar pembuatan majalah dinding

2. Isi majalah dinding kebanyakan di ambil dari internet

Oleh karena itu, pentingnya kegiatan pengabdian dilakukan di SMPN 30 Surabaya adalah guna membangkitkan semangat menulis guna mengisi majalah dinding yang ada. Hal tersebut secara tidak langsung menunjukan bahwa majalah dinding dianggap penting keberadaanya di sekolah. Untuk itu, solusi yang direncanakan telah dilakukan dengan seefektif mungkin sehingga tercapai majalah dinding yang berkualitas dan mendukung pembelajaran menulis dan membaca siswa. Bentuk ideal majalah dinding pada aspek tampilan harus menarik akan lebih indah jika dibuat dengan perpaduan hiasan dan warna. Aspek tata letak juga diperhatikan, tidak hanya mencakup tempat yang strategis, tetapi juga aspek tata letak penyajian materi majalah dinding yang beragam secara proposional, seimbang dan utuh.

\section{METODE PELAKSANAAN}

Dengan memperhatikan analisis situasi dan masalah yang ada di SMPN 30 Surabaya akan diselesaikan dalam program pengabdian. Solusi yang ditawarkan oleh tim pelaksa pengabdian adalah pembuatan media pembelajaran yang berupa mading sebagai wadah menyalurkan kreatifitas siswa dan menumbuhkan minta membaca siswa. Tim pengabdian bekerja sama dengan guru-guru program kerja (POKJA) devisi majalah dinding di SMPN 30 Surabaya dengan membentuk kelompok program kerja (POKJA) majalah dinding siswa SMPN 30 Surabaya. Kegiatan program pengabdian ini dibagi menjadi tiga tahap sesuai dengan konsep lesson study. Muljana (2007), mengemukakan tiga tahapan lesson study yaitu yang pertama Perencanaan (Plan), yang kedua Pelaksanaan (Do) dan yang ketiga Refleksi (See).

Tahap 1 Perencanaan, pada tahap ini, solusi yang ditawarkan adalah memberikan pengarahan sekaligus pelatihan mengenai pengertian, tujuan, manfaat, kelebihan, serta teknis pembuatan majalah dinding. Pada tahap ini juga akan dibentuk kelompokkelompok pokja majalah dinding kelas VII dan kelas VIII yang tiap kelompoknya terdiri atas 5 sampai 7 orang. Masing-masing kelompok akan memilih judul mading sesuai dengan tema yang telah ditentukan oleh tim pelaksana program pengabdian.

Tahap 2 Pelaksanaan, pada tahap ini tim pelaksana pengabdian beserta guru-guru pokja majalah dinding SMPN 30 Surabaya membimbing siswa dalam proses pembuatan majalah dinding dengan judul mading yang telah dipilih masing-masing kelompok. 
Tahap 3 Refleksi, pada tahap ini pelaksana pengabdian dan tim pokja guru-guru mendiskusikan upaya apa yang dilakukan agar mading bisa terawat dan terhindar dari panas dan hujan, dan secara rutinitas mengganti hasil kreativitas siswa dengan yang terbaru.

\section{HASIL DAN PEMBAHASAN}

Pada tahap perencanaan tim pengabdi dari Universitas Dr. Soetomo melakukan koordinasi dengan guru yang bertanggung jawab dalam pokja mading di SMP Negeri 30 Surabaya. Dari koordinasi dengan tim guru-guru pokja mading didapat hasil yaitu penyampaian dan isi materi yang berkaitan dengan mading akan menjadi tanggung jawab tim pengabdi Universitas Dr.Soetomo, kader pokja mading terdiri dari perwakilan dua orang siswa dari kelas VII dan VIII dan pembuatan mading akan dilaksanakan pada tanggal 22 agustus 2019. Materi yang akan disampaikan ini berisi tentang pengertian mading, fungsi mading, manfaat mading, jenis mading, isi mading, alat dan bahan pembuatan mading serta menunjukan contoh mading yang telah disiapkan oleh tim pengabdi dari Universitas Dr. Soetomo.

Tahap pelaksanaan dalam pengabdian ini adalah Pembuatan salah satu contoh mading oleh tim pengabdi Universitas Dr. Soetomo dengan tema kemerdekaan. Pembuatan contoh mading ini dilakukan pada hari minggu tanggal 18 Agustus 2019. Berikut foto yang berkaitan dengan pembuatan contoh mading.

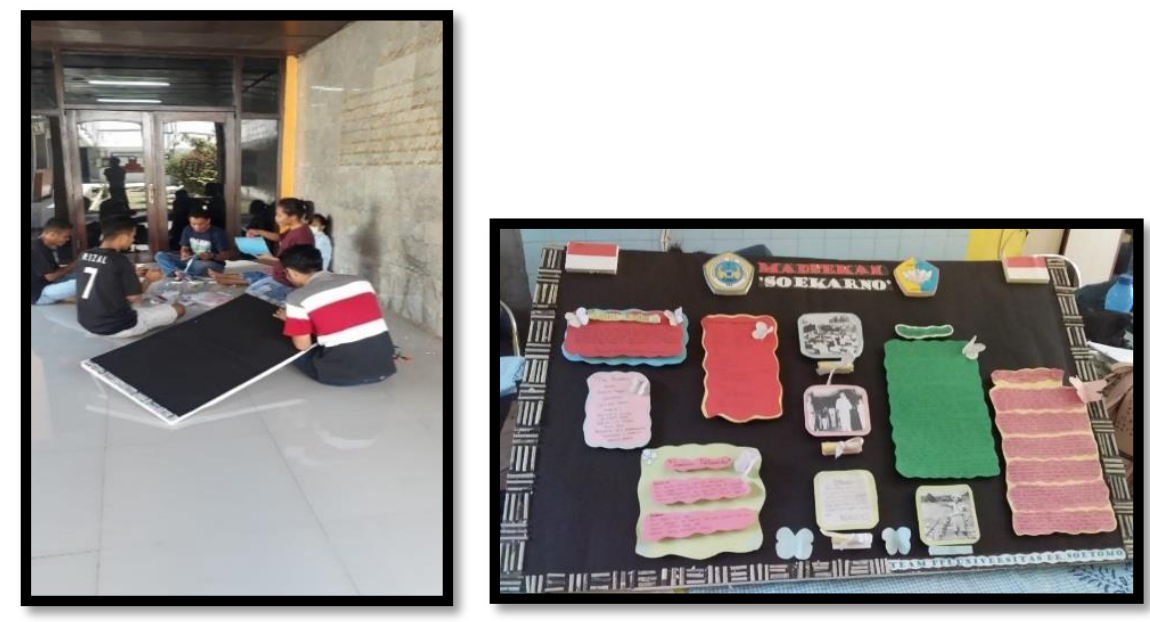

Gambar 2. Pembuatan Contoh Mading

Pemberian materi tentang majalah dinding oleh tim pegabdi dari Universitas Dr. Soetomo yang diikuti oleh 20 siswa kelas VII dan 24 siswa kelas VIII, serta didampingi oleh guru-guru yang bertanggungjawab dalam pokja mading di SMP Negeri 30 Surabaya. Pemberian materi mading dilakukan pada hari kamis tanggal 22 agustus 2019. Setelah selesai menyampaikan materi kader pokja mading dibagi menjadi 8 kelompok yang tiap kelompok terdiri atas 5 sampai 6 orang. Masing-masing kelompok akan didampingi oleh tim pengabdi satu orang. Selanjutnya, tim pengabdi membuat majalah dinding dengan menentukan tema yang disepakati bersama. Adapun tema yang di sepakati setelah te kemerdekaan yaitu tema lingkungan. Tema ini dipilih dikarenakan dengan melihat lingkungan sekolah dengan tumbuhan yang mempunyai banyak manfaat bagi kehidupan 
yang mungkin banyak siswa belum tahu manfaat dari tumbuhan yang ada di lingkungan sekolah.
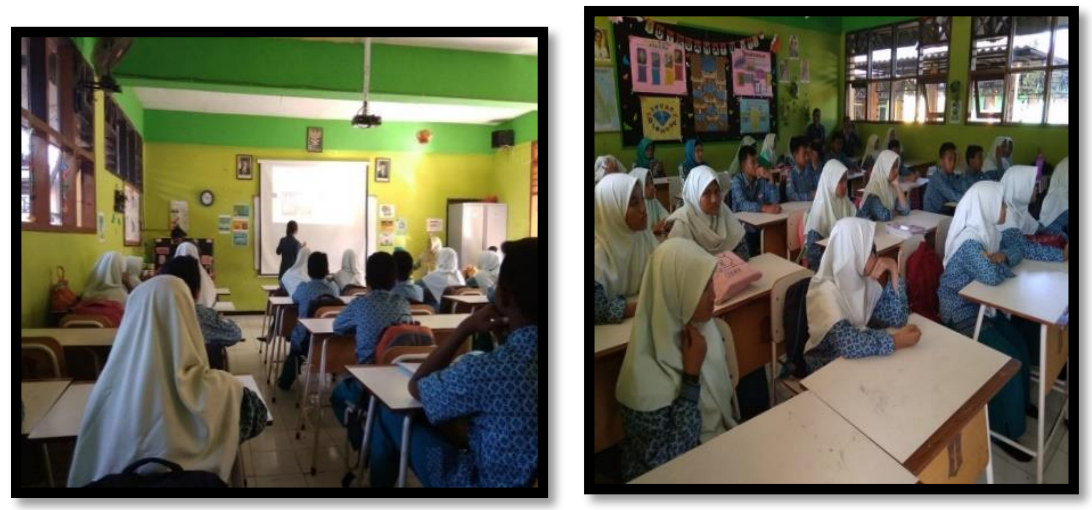

Gambar 3. Penyampaian materi mading kepada siswa

Langkah selanjutnya, yaitu membuat sketsa yang mudah dipahami oleh siswa. Karena siswa lah yang membuat mading sesuai contoh yang dibuat oleh tim pengabdi. Langkah-langkah yang dilakukan oleh siswa selama proses pendampingan dalam pembuatan mading yaitu.

a. Meyediakan bahan dan alat yang akan digunakan. Styrofoam yang berukuran $50 \times 100$ cm ditempelkan kertas berwarna sesuai ukuran styrofoam agar menarik.

b. Setelah temple kertas berwarna pada styrofom, siswa memotong styrofom lainnya dengan ukuran kecil untuk membuat timbun tulisan dan gambar yang akan ditempel pada styrofoam.

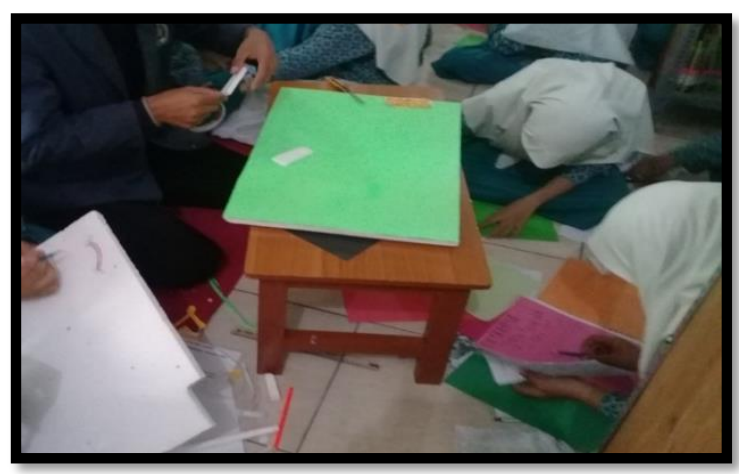

Gambar 4. Siswa memotong Styrofoam

c. Membuat hiasan pinggir pada Styrofoam, hiasannya bisa berupa potongan-potongan koran bekas yang telah digulung, steak es cream dan lan-lain.

d. Tempelkan hasil karya tulis siswa SMPN 30 Surabaya pada styrofoam sehingga menjadi sebuah mading,

e. Tempelkan hasil karya tulis siswa SMPN 30 Surabaya pada styrofoam sehingga menjadi sebuah mading, 


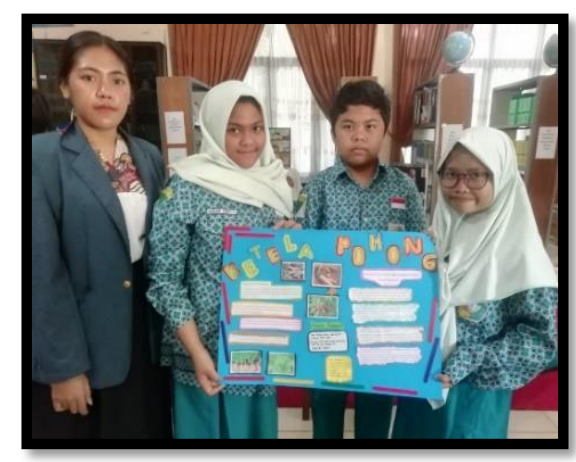

Gambar 5. Mading siswa

Tahap refleksi Tim pelaksana pengabdian dan tim pokja majalah dinding SMPN 30 SURABAYA berdiskusi mengenai hal-hal yang harus diupayakan untuk merawat mading supaya tidak cepat rusak, terhindar dari panas dan hujan, dan secara rutinitas mengganti hasil kreasi siswa dengan yang terbaru untuk madding. Upaya-upaya yang harus dilakukan supaya majalah dinding tetap berjalan dengan baik sesuai harapan semua warga sekolah.

\section{SIMPULAN}

Penyelenggaran kegiatan pengabdian majalah dinding (MADING) "Upaya Meningkatakan Kreativitas Dan Minat Membaca Siswa SMPN 30 Surabaya Dalam Menulis Karya Tulis Melalui Majalah Dinding" dapat dilaksanakan dengan baik melalui serangkaian kegiatan pelatihan dan pendampingan. Berdasarkan pelaksanaan kegiatan pengabdian majalalah dinding dapat disimpulkan hasil pengabdian majalah dinding sebagai berikut :

1. Dengan pelaksanaan kegitan pengabdian dari tim pelaksana pengabdian Universitas Dr. Soetomo tahun ajaran 2019/2020 di SMPN 30 Surabaya, siswa bersama tim pengabdi berhasil membuat mading dua dimensi dengan tampilan yang lebih menarik.

2. Melalui penjelasan dan dialog interaktif antara tim pelaksana majalah dinding Universitas Dr. Soetomo dengan pengurus mading SMPN 30 Surabaya dinilai bahwa kegiatan ini memberikan dampak positif kepada peserta didik maupun guru, yaitu memperoleh pengetahuan dalam menuliskan karya tulis serta pengetahuan tentang majalah dinding. Hal ini terbukti pada tahap pelaksanaan kegiatan pengabdian, dimana tim pengabdi meberikan materi kepada siswa dengan didampingi oleh guru mereka.

\section{DAFTAR RUJUKAN}

Muljana, Slamet. 2007. Lesson Study. Makalah

Asazeo. 2012. "Fungsi Majalah Dinding (Madding) Di Lingkungan Sekolah.", http://asazeo.heck.in/fungsi-majalah-dinding-mading-di-lingkungan-2.xhtml, diakses pada 1 Agustus 2019 puku 9.57 WIB 
Setiawan, Pelatihan Pembuatan Mading....73

Dispendik Kota Surabaya. "Profil SMPN 30 Surabaya",

https://profilsekolah.dispendik.surabaya.go.id/umum/sekolah.php?j=SMP\&npsn= 20532560, diakses pada 2 Agustus 2019 pukul 13.00 WIB 
74 J-Abdipamas, Vol. 4, No. 2 Oktober, 2020 